\title{
On the Question of the Semiotic Typology of Signs
}

\author{
Alexander Shuneyko \\ Komsomolsk-on-Amur State Technical University \\ Correspondence concerning this article should be addressed to Alexander Shuneyko, Department of \\ Linguistics and Intercultural Communication, Komsomolsk-on-Amur State Technical University, 27 \\ Lenina Str., Komsomolsk-on-Amur, Khabarovsky kray, Russian Federation, 681013. \\ E-mail: alexandr-shuneyko@yandex.ru
}

\author{
Olga Chibisova \\ Komsomolsk-on-Amur State Technical University
}

\begin{abstract}
Correspondence concerning this article should be addressed to Olga Chibisova, Department of Linguistics and Intercultural Communication, Komsomolsk-on-Amur State Technical University, 27 Lenina Ulitsa, Komsomolsk-on-Amur, Russian Federation, 681013.

E-mail: olgachibisova@yandex.ru
\end{abstract}

\begin{abstract}
The article is in the context of linguistic and semiotic studies related to theoretical issues of base units' typology, in particular, theoretical linguistics and "pure" semiotics. Sign is one of the basic units of linguistics and semiotics. The way of understanding the nature and structure of the sign essentially influences the nature of almost all studies. The depth, consistency and completeness of perception of signs are reflected in the currently existing classifications of signs. The article fills in a gap in the perception of the sign variety nature in the semiotic and linguistic understanding. It provides a tool for the correct interpretation of a large body of facts related to the secondary use of proper names in the specific function and precedential units in a broad context. The analysis of the actual texts indicates that the current classifications of signs do not reflect in their entirety all the signs which actually exist and function in the space of language and culture. Beyond the limits proposed by these classification schemes are left the phenomena of sufficient frequency. The article based on the appositive and distribution methods describes and analyzes the type of signs that has not been previously perceived by researchers as an independent one and has not been studied at all. This sign is called a bifocal sign and it is consistently described in terms of its specific features which do not allow mixing it with other types of signs. The results show that an adequate interpretation of any text which includes a bifocal sign is impossible without taking into account the specificity of this sign.
\end{abstract}

Keywords: semiotics, linguistics, sign, classification, bifocal sign

More or less accepted by all researchers still having no unified interpretation, the classification of signs suggests their subdivision into the signsindication, iconic signs, codes and symbols (Stanford Encyclopedia of Philosophy, 2015). At the root of this classification are the works of Ferdinand de Saussure and Charles Sanders Peirce.

One of the main provisions of the semiotic theory of Ferdinand de Saussure (1966) is the interpretation of a sign as a bilateral (material and ideal) entity: concept + acoustic image, the relationship between which being asymmetrical (homonyms and synonyms). The second important point of this theory is the idea of arbitrariness (no connection / relationship between the signifier and the signified) and motivation of a linguistic sign.

Charles Sanders Peirce (cited in Murphey, 1961) in any explicit or implicit definition of a sign attached 
greatest importance to its three constitutive elements: a Sign, its Object (with which it interrelates) and its Interpretant (knowledge produced in the mind) that stand in a well-defined type of interrelation. According to him triads are necessary and at the same time sufficient because all other kinds of relations are reducible to them and can be analyzed in their terms. Pierce distinguished the extension, this is the breadth of the concept (a set of objects to which this concept applies), and the intension, this is the depth of the content of the concept.

Nevertheless, the classical classification does not comprise the whole variety of signs. It is due to the fact that new types cannot be detected with the criteria that are the basis of the afore-mentioned classification. It seems quite natural since this classification was not originally intended to cover all the sign features.

Some later theories negate the distinction between the signifier and the signified introduced by Saussure and Peirce and examine a sign not in isolation, but in its interaction with the surrounding context. Louis Hjelmslev (Hjelmslev, 1953 cited in Qvarnstrom, 1971) maintained that language is a collective memory of all the ways which communicate meaning. He considered that the ultimate semiotic unity is "figurae" (a kind of figure of speech) and the internal structure of language is its system. Hjelmslev used "expression plane" and "content plane" instead of signifier and signified and claimed the sign to be a function between the two. He examined and described the combinations of form of content, substance of content, form of expression and substance of expression.

Claude Lévi-Strauss (cited in Avtonomova, 2010) postulated a disconnection between the signifier and the signified and originated the term "a floating signifier" defined by Chandler (2007) as "a signifier with a vague, highly variable, unspecifiable or nonexistent signified" which presupposes the interaction of some signifiers in their isolation from the signified practically in any text.

Lacan (2006) connected the idea of breaking the structure of the sign with the associated problem of interpreting the meaning. According to Lacan, it would be a mistake to say that interpretation is open to all meanings under the pretext that it is a question of the link between the signifier and the signified and therefore uncontrollable link.

Algirdas Julien Greimas (cited in KataliusBoydstun, 1990) searched the laws regulating the mechanisms of generative semiotics. Examining them, he shifted the focus of attention from signs to systems of signification. As a result, he formulated a "Semiotic Square" - the structure fixing the interaction of meanings in discourse. This elementary structure is determined by three relations: opposites, contradictions and complementarity. It can be used as a tool of analyzing not only the individual semantic concepts but also paragraphs and whole texts.

Chief representative of the Tartu-Moscow semiotic school Yuri Mikhailovich Lotman (1973) coined the concept of the semiosphere - the space in which there operate and interact with each other similarly large complexes of different types of signs. It is the culture which is perceived by Lotman as a semiosphere. Thus, to describe a culture means to describe a set of signs.

Eco (1979) offered to interpret the sign not only as a material object but as a guideline for interpretation. These findings were determined by his observations of the interaction of the text's author and a reader. Based on the operating idea of the signs, Eco offered their typology consisting of four parameters: the physical effort necessary for producing the expression, the type-token ratio, the type of continuum and the mode and complexity of articulation.

The Mu Group (Andersson, 2010) attached the traditional classification of signs to the rhetorical constants they studied. They were especially interested in the way in which a particular type of sign functions in the formation of statements with a particular target setting. The Mu Group divided all the rhetorical figures and tropes into four groups: metaplasm (operations with phonetic and / or the graphic appearance of a linguistic sign), metasemem (operation at the semantic level of a linguistic sign), metataksis (operation at the syntactic level of a linguistic sign) and metalogizm (logical operations).

As follows from the above, there we came across a completely different typology which does not essentially intersect with the traditional signs classification as it reveals utterly different characteristics of signs.

This article explores a bifocal sign as one of the new signs that has not yet been described in science.

\section{Materials and Methods}

\section{Materials}

The research comprises a large array of diverse literary texts selected in such a way that they relate to various cultural and literary traditions: collected works of Jorge Luis Borges, Stanisław Lem, Mikhail Yevgrafovich Saltykov-Shchedrin and Andrey Osipovich Novodvorskij. The range of temporal, linguistic, conceptual, aesthetic and ideological characteristics of these texts suggests that a bifocal sign is not a random semiotic phenomenon but a stable one whose existence is not related to the language and literary framework.

The observations made in the course of the research are based on the analysis of literary texts 
which use the proper names which have already been used in other texts. In these texts there was made total sample of material. Particular attention was given to cases in which the connection with the previous text and the use of the name by the author are specifically emphasized. These cases were analyzed using the appositive and distribution methods.

\section{Procedures}

The procedure of analysis generally involves the following algorithmic mechanism:

1. The identification in the literary text of a proper name (name-2) which exterior form allows unambiguous asserting that it has previously been used in another preceding text enshrined in the aesthetic tradition and is an absolute identifier of the previously mentioned object, for example, a character or a title (name-1).

2. The establishment of the interaction mode between the name- 2 and the name- 1 . In total there are three types of this kind:

(1) Name-1 and name-2 are not connected in any way. Such cases are not considered in the article as it is a chance coincidence caused by a limited set of names.

(2) Name-2 fully replicates name-1 through its referential property, for example, someone is reflecting upon the finished book and mentions its characters. Such cases are not considered as well because they are related to precedent phenomena.

(3) Name-2 does not replicate name-1 through its referential property, but still there is a connection between them which is unambiguously confirmed by the context. Such cases are thoroughly analyzed.

3. The ascertainment of the availability of integrated and distinctive semantic features of name- 2 and name- 1 , which belong to the third type of the interaction mode. The differential features are detected through the presence of semantic shifts in contexts and direct descriptions of the designated objects.

4. 4. The attribution of name-2 and name-1 as bifocal sign representers. Referential property and semantics, depending on the type of name, denote both imaginary objects, that is images created within the frames of artistic reality, and real objects, such as concrete works of art.

First of all, visualizing the features of a bifocal sign (in general terms related to the reference of one sign to another) requires comparing it with closely-related phenomena.

Situations where a sign indicates another sign or other signs are habitual (conventional and frequent) for any natural language. They consistently appear in the following cases.

Each case shown in Table 1 is representative of a large group of facts.

The use of the terminology of any meta-language may suggest that the term refers to a sign. This is most clearly seen in the linguistic terminology that practically all, with a few exceptions, is used for nominating other signs of varying degrees of complexity. Since in any developed national language the proportion of metalanguage units is great, such situations are stable and habitual. For example, the sign "sentence" in the statement "The sentence "I am sitting at the table" is a two-member sentence' replaces the sentence "I am sitting at the table".

The actualization of genus-species relationship in any type of speech implies that any linguistic term denotes another sign of varying degree of complexity (or signal). Genus-species relationships are constantly used in speech. They are an integral part of the world conception and are recorded with the help of special categories represented by certain groups in thesauri. Because of this, they literally permeate spontaneous

Table 1

Phenomena resembling a bifocal sign

\begin{tabular}{clll}
\hline No & \multicolumn{1}{c}{ Situation } & \multicolumn{1}{c}{ Specificity of use } & \multicolumn{1}{c}{ Example } \\
\hline 1 & The use of metalanguage & $\begin{array}{l}\text { Any linguistic term means any other } \\
\text { sign of varying degrees of complexity }\end{array}$ & $\begin{array}{l}\text { The sentence "I am sitting at the table" } \\
\text { is a two-member sentence. }\end{array}$ \\
\hline 2 & $\begin{array}{l}\text { The actualization of generic-specific re- } \\
\text { lationship }\end{array}$ & $\begin{array}{l}\text { Any senior sign in the hierarchy rep- } \\
\text { resents a set of junior ones }\end{array}$ & $\begin{array}{l}\text { The words "a sparrow" and "a crow" de- } \\
\text { note birds. }\end{array}$ \\
\hline 3 & The use of estimates of speech & $\begin{array}{l}\text { All estimates of speech indicate other } \\
\text { signs }\end{array}$ & $\begin{array}{l}\text { The letters are lying as if they feel like } \\
\text { sleeping. }\end{array}$ \\
\hline 4 & $\begin{array}{l}\text { The demonstrative reference or descrip- } \\
\text { tion of speech acts }\end{array}$ & $\begin{array}{l}\text { All nominations of speech actions indi- } \\
\text { cate other signs }\end{array}$ & I was in the period of the scandal. \\
\hline 5 & $\begin{array}{l}\text { The characteristics of a person associ- } \\
\text { ated with the peculiarities of his verbal } \\
\text { behavior }\end{array}$ & $\begin{array}{l}\text { All nominations of a person connected } \\
\text { with his/her speech features indicate } \\
\text { other signs. }\end{array}$ & And then we must say: writing! \\
\hline 6 & $\begin{array}{l}\text { The use of the word in the performative } \\
\text { function }\end{array}$ & $\begin{array}{l}\text { In this case, it means another sign - ac- } \\
\text { tion. }\end{array}$ & $\begin{array}{l}\text { Oh, I could do with a drink! In remem- } \\
\text { brance, in remembrance! }\end{array}$ \\
\hline
\end{tabular}


and prepared oral and written speech. The sign "bird" in the expression "The words "a sparrow" and "a crow" denote birds' is used for the nomination of bird species, notably the signs "a sparrow" and "a crow".

All estimates of speech which mention a unit to be assessed or make reference to it denote other signs. 'The letters are lying as if they feel like sleeping' (Osipovich-Novodvorskij, 1877). The word "letters", being a sign itself, signifies specific graphic signs. 'I went, as the saying goes, wherever my feet will carry me' (Osipovich-Novodvorskij, 1877). In this case, "as the saying goes" characterizes a set expression. 'Such talks are especially in keeping with the melody of samovar $\langle\ldots\rangle$ (He) sang sharply, spoke much and well. The speech was like dinner. $<\ldots>$ conversations were deadly liberal and hence deadly boring' (OsipovichNovodvorskij, 1877). The words "speech", "speak", "conversations" indicate the aggregate of other signs, or, from a different point of view, themselves.

All instructions, references or descriptions of specific speech acts, whatever means and ways they are produced with, necessarily involve the use of one sign for the nomination of another. 'I was in the period of the scandal ...' (Osipovich-Novodvorskij, 1877); 'There was a lot of laughter, arguments!' (OsipovichNovodvorskij, 1877); 'Already from this speech, you, 'a fair reader', can conclude that I was not so much logical as great'; 'But what an explanation it was!' (Osipovich-Novodvorskij, 1877). The words "scandal", "argument", "speech", "explanation" indicate some complex signs.

There is a tradition to characterize and name a person based on the specifics of his / her verbal behavior. It manifests itself in the sustainable existence of the individual and group nicknames and common nouns. For example, a talker, a chatterbox, eloquent, snuffling. These names are consistently and constantly used in any language. 'And then we must say: writing!' (Osipovich-Novodvorskij, 1877). The word "writing" means here "literate".

Using a word in a performative function assumes that it represents another sign - the action. This is especially clearly seen in the action, which presupposes the existence of mandatory social contracts. For example, hello, okay, I agree, etc. Each of these actions is actively represented in the communication space. 'Oh, I could do with a drink! In remembrance, in remembrance!' (Osipovich-Novodvorskij, 1877). The word "remembrance" refers to an action that the speaker is about to carry out.

These situations are combined in various ways. For example: 'Though your parents cried, they still blessed you to start out' (Osipovich-Novodvorskij, 1877). The word "blessed" indicates a certain speech act, which is performative. Assessment of speech can be combined with the indication of a certain verbal action as well.
In all these situations the sign serves indicating and / or descriptive (attribute) functions.

The type of using signs, which is different from these situations, is presented in the literal narration or analysis of artistic texts. In these cases, the secondary text uses the same sign as the original text; it is just placed in a new context of interpretation, deformation, or evaluation. For example, the title of A. B. Penkovsky's book "Nina" uses the same sign as Lermontov's poem "Masquerade". The name of the heroine becomes the name of the book (and then the name of the bookstore) without changing its semantics. It is integrally, without any transformation, transferred from one object to another changing denotations or expanding its referential potential. Such use of the name is identical to the direct quotation, and in fact it is a quote: incorporation of somebody else's text elements without changes in one's own text. On a similar citation see Anna Wierzbick's work (1970). Such cases are also common and sufficiently frequent. Here a sign functions as an indicator (or retains the function which it has in the original text).

All illustrated types of situations in which a sign is used to indicate another sign (there are many more of them if their study is not restricted to the sphere of language and speech acts) consistently and logically can be included in the three suppositions of Ockham (suppositio Occam) - the most abstract representation of the types of reference - and can be described in his terms, notably, represented through the personal (suppositio personalis - the term refers to any object it designates), simple (suppositio simplex - the term implies an intention of the soul) and material (suppositio materialis - the term refers to itself) suppositions (Stanford Encyclopedia of Philosophy, 2015).

Existing classifications of signs do not allow, in a strict typological and structural definition of the form, interpreting all the cases of the sign functioning in context. In particular, outside the existing models there remans a considerable amount of facts relating to the use of precedent proper names in the situation of a secondary particular or point nomination in relation to the objects that exhibit an accented connection with objects, initially called by these names, and at the same time oppose them. Such cases are many. They are recorded in a special type of communicative situations fixed in the procedure of the analysis of the above-mentioned texts.

\section{Results and Discussion}

This research has singled out a particular type of situations which is basically not reduced to the listed 
above and which represents a specific use of a sign. These are the cases when in one artistic text there acts a character which has previously acted by the same name in another text. At that this coincidence of names is not accidental; it was originally included in the author's artistic message. With the help of this name the author of the text makes conscious reference to solve certain aesthetic problems.

Such cases are not something exceptional or unique either. They can be traced, for example, in M. Y. Saltykov-Shchedrin's essays “The Well-Meant Speeches" (Благонамеренные речи) and "Messrs Molchalins" (Господа Молчалины). The heroes of these essays Derzhimorda and Molchalin are taken from the works of Russian classical literature N. Gogol's comedy "The Government Inspector" (Ревизор) and A. S. Griboyedov's comedy "Woe from Wit" (Горе от ума), respectively. It should be emphasized that it is not about the cases where the proper name functions as a common noun (this is a well-known type which is ascribed to the above situations and suppositio Occam), but it is about the cases where it nominates another independent character with the reference to the predecessor.

The hero-narrator of the story "Episode in the life of any surfactants or crows" (Эпизод из жизни ни павы, ни вороны) by A. S. Osipovich-Novodvorskij (1877) says about his family:

"My grandfather - 'the spirit of denial, the spirit of doubt' or just Demon - died a natural death, in his bed, probably bored with flying above the peaks of the Caucasus"; "All of us gathered near his bed: my father Pechorin, I, my brothers Rudin and Bazarov'; 'In the room, except for the persons stated above, there was no one. Onegin was absent, because he was not my father's brother, as some claim, but only a distant cousin, ten times removed cousin; Oblomov was also absent, for the simple reason that he is Onegin's, not Pechorin's son'; 'My grandfather died in a village of Nebyvalovka, Pechorin's estate (soon, however, it was sold for the debts), after a duel of my father with ill-fated Grushnitsky, after an affair with princess Mary'; 'My brothers were not with me. They had been taken to the foster fathers and mothers. You know the subsequent history of both from the excellent biographies written by Turgenev'.

These contexts (there are more similar cases in the story) mention the names: Demon, Pechorin, Rudin, Bazarov, Onegin, Oblomov, Grushnitski, Mary. They are mentioned with explicit references (in the course of the narrative this relationship for Demon,
Pechorin, Rudin and Bazarov is specially emphasized) to the sources in which they originally functioned: A. S. Pushkin's poem "Angel” (Ангел) and verse novel "Yevgeny Onegin” (Евгений Онегин), М. Y. Lermontov's poem "Demon" (Демон) and story "A Hero of Our Time” (Герой нашего времени), I. S. Turgenev's novels "Rudin" (Рудин) and "Fathers and Sons" (Отцы и дети), I. A. Goncharov's novel "Oblomov" (Обломов).

Though with a strict reference to the original text, without which there simply will be no produced artistic effect, these names are mentioned not as a quote. The characters bearing the same names do not exhibit the same behaviour. It turns out that Demon, scarcely subject to death, had a family and died in his estate surrounded by sons and grandsons, and then the lackey dropped him into the river Lethe. Pechorin, who also had no family in the source code, was the son of the Demon and the father of Rudin and Bazarov, who were the offsprings of different parents in the original text. Besides Pechorin is distantly related to Onegin, Oblomov's father and so on.

In most cases these characteristics represent the ironic reinterpretation of the then existing critical practice which loved to determinate "kinship" between the characters of the various texts. The semantics assigned to the name of the character (no matter whether it is defined as an associated field or as a strict signification) consists of the substantial characteristics of the character. As a result, Pechorin is the one who had no family and the one who had quite a specific family; Onegin is a person who had no son and the one who had a son Oblomov, and so on.

Allnamesinthereproducedcontextssimultaneously preserve the old semantics and are endowed with new meanings. All of these names are both independent and dependent signs. They are simultaneously able to operate in isolation from the context of the original work and are not able to do it, because the insulation causes the loss of their semantics, and they cease to perform those functions or to produce the artistic effect, which they are intended to implement. Thus, the sign (proper noun) denotes and, at the same time, does not denote itself; it refers and, at the same time, does not refer to its identity. This is a bifocal sign.

The differences between the structure of a sign in the traditional sense and the structure of a bifocal sign can be presented starting from the model of the semiotic triangle proposed by Ogden and Richardson (1923) displayed in Fig. 1. This model captures the interaction between the three basic components of the sign: the sign itself, its interpretant and object. Here S stands for Sign - material form of the sign (its sound or graphic complex); I means Interpretant - inner form of the sign (its semantic complex which corresponds to it); O is Object - real or imaginary object for naming 


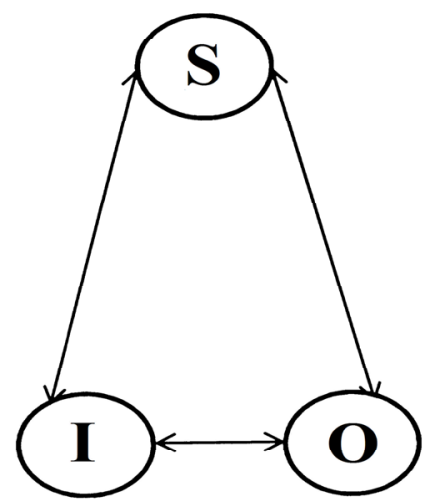

Figure 1. A traditional sign.

which the sign is used.

A bifocal sign in Figure 2 has a principally different structure. It has, in contrast to the traditionally understood sign, two (or more) material forms, two (or more) inner forms and two (or more) objects. Nevertheless, from the perspective of its use and existence nature, it is a single sign. Each of the components of a bifocal sign's duality is not an independent sign; it is a part of the indivisible unity.

It should be emphasized that the integrity of the bifocal sign is not determined by the fact that it consists of two or more base triangles, but by the fact that it is an inseparable unity. A bifocal sign is not a composition of elementary signs; it is a new type of elementary signs with a distinctive typological structure.

The integrity of a bifocal sign gives rise to the functional nature of the sign, its purpose, and effects generated by it. This integrity is predetermined by a special type of situations the essence of which is the establishment and consolidation of the inextricable link between two nominations of two different objects. A bifocal sign is a unit which is simultaneously represented in more than one text (in the broadest sense). Its existence is determined by the author who seeks to emphasize one or another type of interaction of his own text with the pre-existing text. Bifocal signs perform nominative function.

Forked integral signifiers of bifocal signs are not necessarily proper names. This part can also be performed by common nouns, or the whole phrases (deformed quotes). Compare a bifocal sign with signifier "my uncle" or "Yevgeny Onegin's uncle". The first example in taken from A. S. Pushkin's "Yevgeny Onegin" (translation by $\mathrm{Ch}$. Johnston), retrieved from http://lib.ru/LITRA/PUSHKIN/ENGLISH/onegin j.txt

My uncle - high ideals inspire him; but when past joking he fell sick, he really forced one to admire him -and never played a shrewder

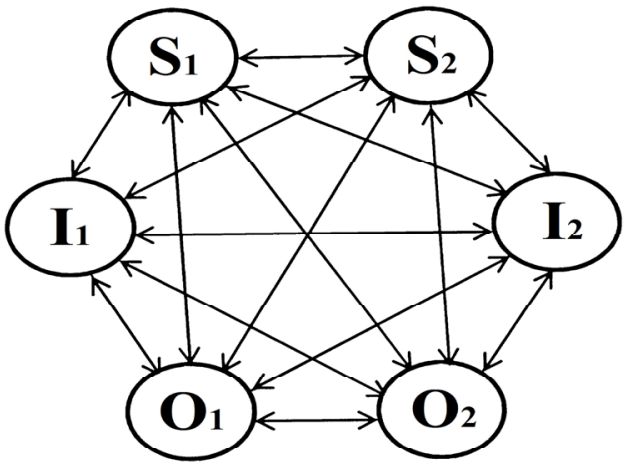

Figure 2. A bifocal sign.

trick.

The second one from the song of Psoi Korolenko is retrieved from http://www.megalyrics.ru/lyric/ psoi-korolienko/moi-diadia-dot-silnyi-kak-orlan-bylobustroien-v-zhizni-kruto-dot.htm:

My uncle, as strong as an eagle, well-

fixed was in life to the brim: he called a

halt to a minute, and life could transform in a dream.

This bifocal sign has numerous homonyms. In the poem below, retrieved from http://www.hohmodrom. $\mathrm{ru} /$ project.php?prid $=95534$, it is a homonym, not a bifocal sign itself, because its appearance presupposes the presence of unified internal references of the subsequent component to all previous ones.

My uncle - high ideals inspire him, when he was going on the cops. He really had the right to do it. Don't give a neighing like a horse.

Forked integral denotation of a bifocal sign (its semantics) is not a simple sum of the meanings of its components. Their convergence poses special effects of semantic likeness/difference, similarity/opposition. They complement actual text features and mark a specificity of a bifocal sign's meaning, which is often ambivalent or in the direction of ambivalence.

A bifocal sign is present simultaneously in two places (texts), and in this sense it is comparable to the elementary particle that, according to quantum mechanics, can be simultaneously in two points of the space. From another point of view, a bifocal sign can be compared to a diphthong, within which two separate sounds act as a single entity.

Bifocal signs are widely represented in literary parodies and various biographies (and partly in autobiographies). The functionality of these speech genres is based precisely on the nature of bifocal signs, because without reference to the preceding text or a real object, taken in isolation, they completely lose the 
ability to produce the effect which they were created to implement. In the case of biographies, a bifocal sign can become more complex and, strictly speaking, transform into a multifocal.

While writing, a biographer can use a model "a real person-a text about him”. Then in case of specialintent, fundamental impossibility or simple unwillingness of the biographer to adequately describe the object of the narrative, a bifocal sign appears. When a model "a real person - a source fixing his peculiarities (one or more) - the text about him" is used, there can appear a multifocal sign which is a special case of a bifocal one and hardly has any fundamental features of its own. In both cases there is a shift in the semantics and its divergence.

Another type of texts where bifocal signs are well represented is different cases of lies and misinformation. The peculiarity of these texts is that their authors deliberately seek to portray bifocal signs as traditional and herewith to create the wrong idea about the reality in the data receiver.

The degree of bifocal sign perception completeness depends on the level of language competence of the receiver. The one with a low level of competence having no idea of the source text, perceives a bifocal sign as traditional and, therefore, inadequately reads the entire text, impoverishes it, endows it with nonexistent meanings or takes a lie for the truth (and vice versa).

In a broad semiotic aspect, the bifocal signs can be found in replicas of products, forgery, caricatures, and various genres of painting. These signs function as units of language: caricatures = literary parodies, replicas and fakes $=$ lies and misinformation, and various genres of painting $=$ different genres of literature. The difference between these bifocal signs lies only in their physical media (signifiers), but not in their nature or structure.

Another broad area of the bifocal sign's presence is literature and theater. In the case of theater, bifocal signs occur when a performance is not originally related to the drama, such as "The Village of Stepanchikovo" (Село Степанчиково и его обитатели) staged by the Maly Theatre (premiere April 28, 2013). In the case of a movie, it is the transfer of literary texts and sequels on the screen, for example "Solaris" (Солярис) directed by Andrei Tarkovsky (1972) and "Solaris" directed by S. Soderbergh (2002).

All of the above types of texts are only oriented at bifocal signs but do not consist exclusively of them. They also have a high proportion of direct quotations. The more citations these texts contain, the closer they are to the original text; the more bifocal signs they have, the farther they move from it.

The vector of creation (emergence) of bifocal signs is always sent back (backwards, in the past), they appear due to the interaction of a new text with the previous one. In this they differ from the vector of renaming (the acquisition of a new name by the sign), which is always directed forward (in the future). Even in cases where the sign returns its past name (St. Petersburg - Petrograd - Leningrad - St. Petersburg) the name is functionally in the future and rejects the past tradition or any part of it. On the contrary, a bifocal same sign confirms past tradition, addressing the data receiver to it.

Even in the cases where the name and description (semantics) of the object initially occur in one of imaginary worlds (robot of Karel Čapek, a submarine of Jules Verne, and so on), and then the object is constructed in a real world, a bifocal sign may occur only as a reference to the prior nomination. A bifocal sign actualizes the past, while the renaming seeks to erase it. In a broad cultural context bifocal signs are clamps uniting imaginary worlds into a single unit. They show the connection between imaginary worlds, indicate their spatial and temporal continuity.

Special attention should be given to the comparison of bifocal signs and precedent phenomena, the ratio of which in general is subject to the rule: any bifocal sign, in principle, can be perceived as a precedent phenomenon, but not any precedent phenomenon is a bifocal sign. The scope of intersection between these objects - different in respect of linguistics and semiotics - is limited to proper names and nominative groups which obtain a new reference in a new text. It is important that in this case the proper names are not only anthroponyms. They may be the names of objects as well. For example, the creative legacy of Jorge Luis Borges and Stanislaw Lem contain many bifocal signs - the names of literary works that by their very presence and artistic embodiment generate new imaginary realities. On the other hand, quotations, names and nominative groups which, when used in the new text, retain their old reference are precedent phenomena but not bifocal signs. Traditionally, such cases are perceived by native speakers as allusions or references. Their functionality does not imply any augment of new meanings; it is only a direct indication of the cultural tradition according to which a particular type of dialogue related to actualizing the primary source authority is carried on.

Precedent phenomena operate in all functional styles except for official business but they are most arresting in media. More often than not, the researchers do not distinguish between precedent phenomena, bifocal signs and cases of their superposition. They interpret the full set of facts as a whole, which affects the quality of the interpretation. It is momentous to emphasize that the precedent texts perform the categorization of the existing reality while bifocal signs always create some of its new segments. That is 
for the latter, in this aspect, the predominant feature is generating.

A bifocal sign captures not only a new object but its integrated perception as a unit which already has some history in the field of culture. It can be argued that a bifocal sign at the moment of its occurrence and translation always possesses a prospective vector of semantic development, but a precedent text can have both a prospective (when it coincides with a bifocal sign) and retrospective (when it does not coincide with it) vector of semantic development.

Another criterion for differentiation is that the precedent texts themselves may be diffuse by nature, that is, they may simultaneously refer to several texts without specifying (to a book and a film, a poem and a romance, etc.). As a bifocal sign always has a concrete nature, that is, it refers to strictly defined denotata which combine into a single unit.

There is only one functional similarity between precedent texts and bifocal signs: both of them in their perception are connected with the recipient's background knowledge. But the resemblance is external; it is not meaningful and it is not related to the structural characteristics of the objects.

\section{Conclusion}

The phenomenon of the sign from the time of Pierce and Saussure has consistently attracted the attention of researchers. Signs are considered in their relation to other objects of varying breadth and complexity and from the aspect of the mechanisms of their occurrence in communication. In so doing, the basic classification of signs varies but remains unchanged. At the same time, it does not allow to interpret the whole variety of sign objects.

There is a large number of facts that are outside the types which are traditionally singled out. It is possible to describe the semiotic specificity of these facts only by using a new classification. It does not exclude or deny the previous one; it has a complementary character. It is based on a due account taken of the way in which the sign functions in the context. The functioning of the sign in the context as a basis for identifying its specific features indicates the existence of two different groups of situations.

The first group is diverse and still not consistently typologized situations in which a sign is used instead of another sign. In total there are six situations of this kind. Each of them is interesting in the communicative context but does not show any previously unknown semiotic potential.

The second group is quite different; it allows discovering the context of using previously unknown type of sign. From the perspective of the second group, the sign of a special type is a bifocal sign. This is a special semiotic unit in which all components are doubled and their interaction is subject to the availability of bi-directional links between them.

A bifocal sign never exists in one particular context. It is always deconcentrated at least between two texts. It implements various functions and its integrated dual semantics is ambivalent by its very nature.

The correct reading of any text assumes, first of all, the true reading of the aggregate of signs contained in it. Using the concept of bifocal sign and accounting of features of this type of signs identified and fixed in the article will allow a greater degree of consistency and adequacy in perceiving and analyzing different texts. Since bifocal signs are special structural and semantic formations, their perception by the data receiver should be different from the perception of other types of signs. The interpretation of bifocal signs contained in particular texts and statements is always wider than the borders of these texts and statements. For this reason, bifocal signs should be assessed as special linguistic and cultural clamps, as factors that ensure the unity of specific languages and cultures.

\section{Limitation and Future Directions}

The conclusions obtained in this study, are mostly limited to the material of fiction language and are not fully extrapolated to the whole semiotic space.

The most promising directions of further research seem to be the following. First, it may be productive to consider how the bifocal signs are represented in different functional styles, what statistical and substantive laws their operation is subject to in them. Second, it is necessary to answer the question if bifocal signs can appear spontaneously, unconsciously, without deliberate will of the speaker. Third, it should be found out what functional capacity is inherent in the use of bifocal signs in spontaneous everyday speech, what restrictions and priorities can be found there. And, finally, it should be established whether the totality of the bifocal signs is an independent semiotic subsystem or whether they are a set of odd local units performing their functions separately and independently from each other.

Addressing all these issues will create a coherent theoretical basis for the meaningful use of bifocal signs in different communication environments.

\section{References}

Andersson, F. (2010). Groupe $\mu$ and "the system of plastic form" - for an evaluation. Retrieved November 11, 
2015 from http://epublications.unilim.fr/revues/ as/3097

Avtonomova, N. S. (2010). Claude Levi-Strauss - in memoriam: Lessons of structural anthropology and humanism of the XXI century. Russian Studies in Philosophy, 8, 97-107.

Chandler, D. (2007). Semiotics: The basics (2nd ed.). London, UK: Routledge.

de Saussure, F. (1966). Course in general linguistics. New York, NY: McGraw-Hill.

Eco, U. (1979). The role of the reader: Explorations in the semiotics of texts. Bloomington, IN: Indiana University Press. Retrieved November 19, 2015 from http://www.goodreads.com/book/show/10528. The_Role_of_the_Reader

Hohmodrom. (2015). Smeshniye stikhi [Funny poems]. Retrieved July 17, 2015 from http://www. hohmodrom.ru/project.php?prid=95534

Katalius-Boydstun, M. (1990). The semiotics of A. J. Greimas: An introduction. Lituanus, 3(36). Retrieved November 15, 2015 from http://www. lituanus.org/1990_3/90_3_02.htm

Korolenko, P. (n.d.). Moy dyadya (My uncle). Retrieved June 2, 2015 from http://www.megalyrics.ru/lyric/ psoi-korolienko/moi-diadia-dot-silnyi-kak-orlanbyl-obustroien-v-zhizni-kruto-dot.htm

Lacan, J. (2006). Écrits. New York, NY: W. W. Norton $\&$ Co.
Lotman, Y. M. (1973). Articles on the typology of culture. Materials for the course of literary theory. Retrieved November 19, 2015 from http://rutracker.org/ forum/viewtopic.php?t=4822032

Murphey, M. (1961). The development of Peirce's philosophy. Cambridge, MA: Harvard University Press.

Ogden, C. K., \& Richards, I. A. (1923). The meaning of meaning. Retrieved July 21, 2015 from http:// courses.media.mit.edu/2004spring/mas 966/ Ogden\%20Richards\%201923.pdf

Osipovich-Novodvorskij, A. S. (1877). Episode in the life of any surfactants or crows. Retrieved October 09, 2015 from http://az.lib.ru/o/ osipowichnowodworskij_a_o/text_0010.shtml

Pushkin, A. S. (n.d.). Eugene Onegin. (Ch. Johnston, Trans.). Retrieved June 14, 2015 from http://lib.ru/ LITRA/PUSHKIN/ENGLISH/onegin_j.txt

Qvarnstrom, B-O. (1971). Review: Louis Hjelmslev, Omkring Sprogteoriens Grundlaeggelse; Louis Hjelmslev, Prolegomena to a theory of language. Journal of Symbolic Logic, 36, 153-154.

Stanford encyclopedia of philosophy. (2015). Retrieved August 15, 2015 from http://plato.stanford.edu/

Wierzbick, A. (1970). Descriptions or quotations? In Sign, language, culture (pp. 627-644). The Hague, Netherlands: Mouton. 